\title{
PELABELAN SUPER MUKA ANTI-AJAIB PADA KELAS GRAF PLANAR
}

Super Anti-Magic Labelings of A Class of Planar Graphs

\author{
CHRISTIAN HALIM ${ }^{1}$, FRANCIS Y. RUMLAWANG ${ }^{2}$, HENRY W. M. PATTY ${ }^{3}$ \\ ${ }^{1}$ Kelompok Aljabar Jurusan Matematika FMIPA UNPATTI \\ ${ }^{2,3}$ Staf Jurusan Matematika FMIPA UNPATTI \\ J1. Ir. M. Putuhena, Kampus Unpatti, Poka-Ambon, Maluku \\ e-mail: christianhalim11@yahoo.com1,rumlawang@yahoo.com, henry_4t00@yahoo.com
}

\begin{abstract}
ABSTRAK
Penelitian ini berfokus pada pelabelan super anti-ajaib dari graf planar tipe $(\boldsymbol{a}, \boldsymbol{b}, \boldsymbol{c})$. Akan ditunjukkan bahwa suatu kelas dari graf planar yang didefinisikan menggunakan graf lengkap dan suatu kelas dari graf planar yang didefinisikan menggunakan graf bipartit lengkap adalah $(\mathbf{1}, \mathbf{1}, \mathbf{0})$ dan $(\mathbf{1}, \mathbf{1}, \mathbf{1})$ super anti-ajaib dengan keadaan tertentu.
\end{abstract}

Kata kunci : Graf bipartit lengkap, graf lengkap, graf planar, pelabelan super anti-ajaib $(\mathbf{1}, \mathbf{1}, \mathbf{0})$, pelabelan super anti-ajaib $(\mathbf{1}, \mathbf{1}, \mathbf{1})$.

\section{PENDAHULUAN}

Diberikan $G$ suatu graf bidang, berhingga, sederhana, tak berarah, dan tak terhubung, dengan himpunan titik $V$, himpunan sisi $E$, dan himpunan muka $F$. Pelabelan graf adalah fungsi yang memetakan elemenelemen pada graf ke himpunan bilangan (umumnya bilangan bulat positif atau tak negatif).

Pada penelitian ini, dibahas pelabelan total, yaitu pelabelan dengan domain $V \cup E$ dan pelabelan dengan domain $V \cup E \cup F$, disebut pelabelan $(1,1,1)$. Secara formal pelabelan total merupakan fungsi bijektif

$$
\lambda: V \cup E \rightarrow\{1,2, \ldots,|V|+|E|\} .
$$

Bobot muka dari pelabelan merupakan jumlahan dari semua label (jika ada) yang dimiliki oleh muka, sisisisi, dan titik-titik yang mengelilinginya.

Pelabelan pada suatu graf bidang $G$ disebut $d$-muka anti-ajaib, jika untuk setiap bilangan $s$, himpunan dari bobot muka dengan s-sisi, $\omega_{s}=\left\{a_{s}, a_{s}+d, a_{s}+\right.$ $\left.2 d, \ldots, a_{s}+\left(f_{s}-1\right) d\right\}$ untuk suatu bilangan bulat $a_{s}>0$ dan $d \geq 0$, dimana $f_{s}$ adalah banyak muka dengan $s$-sisi. Pelabelan tersebut dikatakan super, jika label terkecil yang mungkin muncul pada titik-titik.

Sebuah kelas dari graf planar dapat diperoleh dengan cara menghilangkan beberapa sisi dari graf lengkap. Kelas dari graf planar yang diperoleh dinotasikan dengan $P l_{n}$ dan mengandung jumlah maksimum dari sisi-sisi yang mungkin dalam suatu graf planar dengan $n$ titik.

Didefinisikan kelas graf planar lain yang diperoleh dari graf bipartit lengkap $K_{m, n}$, dengan $m, n \geq 3$ dengan menghilangkan beberapa sisi untuk menjadikannya graf planar, disebut kelas planar bipartit dan dinotasikan dengan $P l_{m, n}$. Graf $P l_{m, n}$ mempunyai jumlah maksimum sisi yang mungkin untuk suatu graf bipartit planar.

Penelitian ini difokuskan pada pelabelan super antiajaib pada kelas $P l_{n}$ dan $P l_{m, n}$ dari graf planar.

\section{TINJAUAN PUSTAKA}

Dalam [2]. [3], dan [5], diberikan definisi-definisi serta teori yang penulis gunakan dalam penulisan ini. Dalam [1], [5], dan [6], diberikan pelabelan-pelabelan lain yang telah diteliti sebelumnya. Dalam [6], Tilukay, dkk. memberikan pelabelan total super $d$-muka anti-ajaib dari hasil korona dari graf pohon dengan $r$ buah graf lintasan. Dalam [4], Ramanjaneluyu memberikan pelabelan pada graf yang sama namun belum umum untuk setiap graf sehingga penulis mendefinisikan pelabelan lain yang menyempurnakannya. 


\section{HASIL DAN PEMBAHASAN}

\section{Kelas $\boldsymbol{P} \boldsymbol{l}_{m, n}$ dari Graf Lengkap}

Misal $K_{n}$ graf lengkap dengan $n$ titik $V_{n}=\{1,2, \ldots, n\}$. Kelas dari graf $P l_{n}$ memiliki himpunan titik $V_{n}$ dan himpunan sisi $E_{n}=E\left(K_{n}\right) \backslash\{(k, l): 3 \leq k \leq n$, $k+2 \leq l \leq n\}$.

Graf $P l_{n}$ dapat dideskripsikan sebagai berikut:

1. Letakkan titik $v_{1}, v_{2}, \ldots, v_{n-2}$ pada garis vertikal dengan $v_{1}$ di paling bawah, dan $v_{n-2}$ di paling atas.

2. Kemudian letakkan titik $v_{n-1}$ dan $v_{n}$ pada garis horizontal dengan $v_{n-1}$ berada di sebelah kiri $v_{n}$, sedemikian sehingga titik-titik $v_{n}, v_{n-1}$, dan $v_{n-2}$ membentuk muka segitiga (lihat Gambar 1).

Sisi-sisi dari graf $P l_{n}$ sekarang dapat digambarkan tanpa ada sisi yang saling berpotongan. Setiap muka pada graf ini panjangnya 3 .

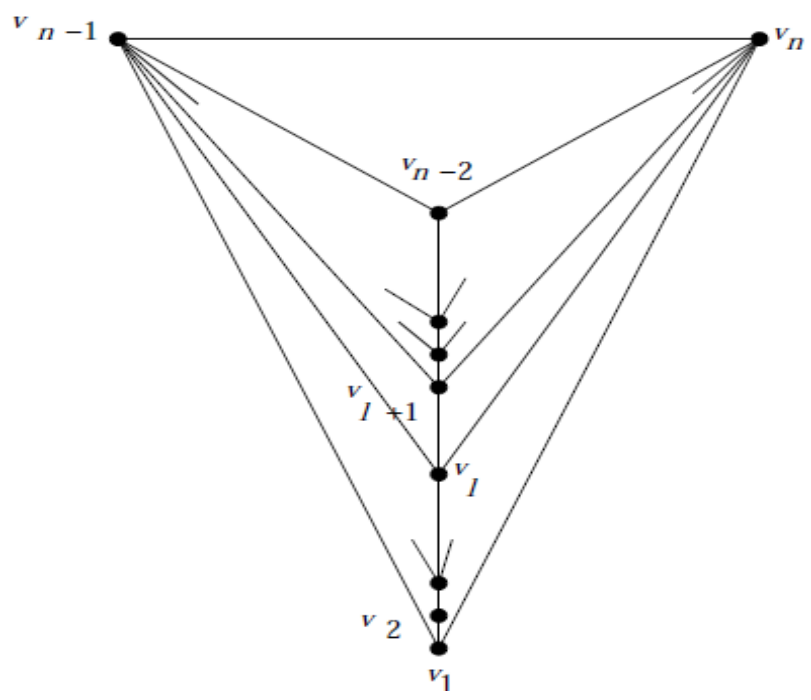

Gambar 1. Graf $P l_{n}$

\section{Teorema 3.1.}

Graf $P l_{n}$ dengan $n \geq 5$ memiliki pelabelan super anti-ajaib tipe $(1,1,0)$.

\section{Bukti.}

Diberikan suatu kelas planar $P l_{n}(V, E)$ dengan $n$ titik, yaitu $v_{1}, v_{2}, \ldots, v_{n}$ dan $3 n-6$ sisi. Didefinisikan fungsi bijektif $f: V \cup E \rightarrow A$, dengan $\quad A=\{1,2, \ldots, 4 n-6\}$ sebagai berikut :

Pelabelan titik :

Pelabelan sisi :

$$
f\left(v_{i}\right)=i, \text { untuk } 1 \leq i \leq n
$$

$$
\begin{aligned}
& f\left(v_{n-1}, v_{i}\right)=2 n-1-i, \text { untuk } 1 \leq i \leq n-2 \\
& f\left(v_{n}, v_{i}\right)=3 n-3-i, \quad \text { untuk } 1 \leq i \leq n-2
\end{aligned}
$$

$$
\begin{aligned}
& f\left(v_{n-1}, v_{n}\right)=3 n-3 \\
& f\left(v_{i}, v_{i+1}\right)=4 n-5-i, \text { untuk } 1 \leq i \leq n-3
\end{aligned}
$$

Karena label-label terkecil diberikan pada himpunan titik-titik, maka pelabelan ini merupakan pelabelan super. Selanjutnya dapat dilihat bahwa jumlah muka dalam pada $P l_{n}$ adalah $2 n-5$. Muka yang terbentuk dari titik-titik $v_{n}, v_{n-1}, v_{n-2}, v_{n}$ memiliki bobot $9 n-6$. Sebanyak $n-3$ muka yang terbentuk dari titik-titik $v_{l}, v_{l+1}, v_{n-1}, v_{l}$, untuk $1 \leq l \leq n-3$ memiliki bobot $9 n-8-l$, dan sisanya yaitu sebanyak $n-3$ muka yang terbentuk dari titik-titik $v_{l}, v_{l+1}, v_{n}, v_{l}$, untuk $1 \leq l \leq n-$ 3 memiliki bobot $11 n-11-l$.

Perhatikan bahwa:

1. Hanya terdapat 1 muka dengan bobot $9 n-6$.

2. Terdapat $n-3$ muka dengan bobot $9 n-8-l$, untuk $1 \leq l \leq n-3$, yaitu :

$$
\begin{gathered}
l=1 \rightarrow 9 n-8-1=9 n-9 \\
l=2 \rightarrow 9 n-8-2=9 n-10 \\
\quad \quad \quad \\
l=n-4 \rightarrow 9 n-8-(n-4)=8 n-4 \\
l=n-3 \rightarrow 9 n-8-(n-3)=8 n-5
\end{gathered}
$$

Sehingga bobot terkecil adalah $8 n-5$ dan bobot terbesar adalah $9 n-9$.

3. Terdapat $n-3$ muka dengan bobot $11 n-11-l$, untuk $1 \leq l \leq n-3$, yaitu :

$$
\begin{gathered}
l=1 \rightarrow 11 n-11-1=11 n-12 \\
l=2 \rightarrow 11 n-11-2=11 n-13 \\
\quad \vdots \\
l=n-4 \rightarrow 11 n-11-(n-4)=12 n-7 \\
l=n-3 \rightarrow 11 n-11-(n-3)=12 n-8
\end{gathered}
$$

Sehingga bobot terkecil adalah $12 n-8$ dan bobot terbesar adalah $11 n-12$.

Dapat disimpulkan bahwa untuk $n \geq 5$ dan $1 \leq l \leq$ $n-3$ bobot-bobot tersebut memenuhi:

$$
9 n-8-l<9 n-6<11 n-11-l .
$$

Atau dengan kata lain, setiap muka memiliki bobot yang berbeda.

Dengan demikian graf $P l_{n}$ dengan $n \geq 5$ memilki pelabelan super anti-ajaib tipe $(1,1,0)$.

\section{Akibat 3.2}

Graf $P l_{n}$ dengan $n \geq 5$ memiliki pelabelan super antiajaib tipe $(1,1,1)$. 


\section{Kelas $P l_{m, n}$ dari graf planar bipartit}

Diberikan graf bipartit lengkap $K_{m, n}\left(V_{m}, U_{n}\right)$ dengan $V_{m}=\left\{v_{1}, \ldots, v_{m}\right\}$ dan $U_{n}=\left\{u_{1}, \ldots, u_{n}\right\}$. Kelas graf $P l_{m, n}$ mempunyai himpunan titik $V=V_{m} \cup U_{n}$ dan himpunan sisi $E=E\left(K_{m, n}\left(V_{m}, U_{n}\right)\right) \backslash\left(v_{l}, u_{p}\right):\{3 \leq l \leq$ $m$ dan $2 \leq p \leq n-1\}$.

Jumlah titik dan sisi pada graf $P l_{m, n}$ adalah $m+n$ dan $2 m+2 n-4$.

Selanjutnya algoritma pelukisan graf $P l_{m, n}$ yang digunakan adalah sebagai berikut :

1. Tempatkan titik-titik $u_{1}, u_{2}, \ldots, u_{n}$ sepanjang garis horisontal dengan $u_{1}$ sebagai titik ujung kiri dan $u_{n}$ sebagai titik ujung kanan.

2. Tempatkan titik-titik $v_{m}, v_{m-1}, \ldots, v_{3}, v_{1}$ sepanjang garis vertikal dengan $v_{1}$ sebagai titik ujung bawah dan $v_{m}$ sebagai titik ujung atas sedemikian hingga $v_{m}, v_{m-1}, \ldots, v_{3}, v_{1}$ berada di atas $u_{1}, u_{2}, \ldots, u_{n}$.

3. Tempatkan titik $v_{2}$ di bawah $u_{1}, u_{2}, \ldots, u_{n}$ sedemikian hingga $v_{1}, u_{k}, v_{2}, u_{k+1}$ membentuk muka dengan panjang 4 untuk $1 \leq k \leq n-1$.

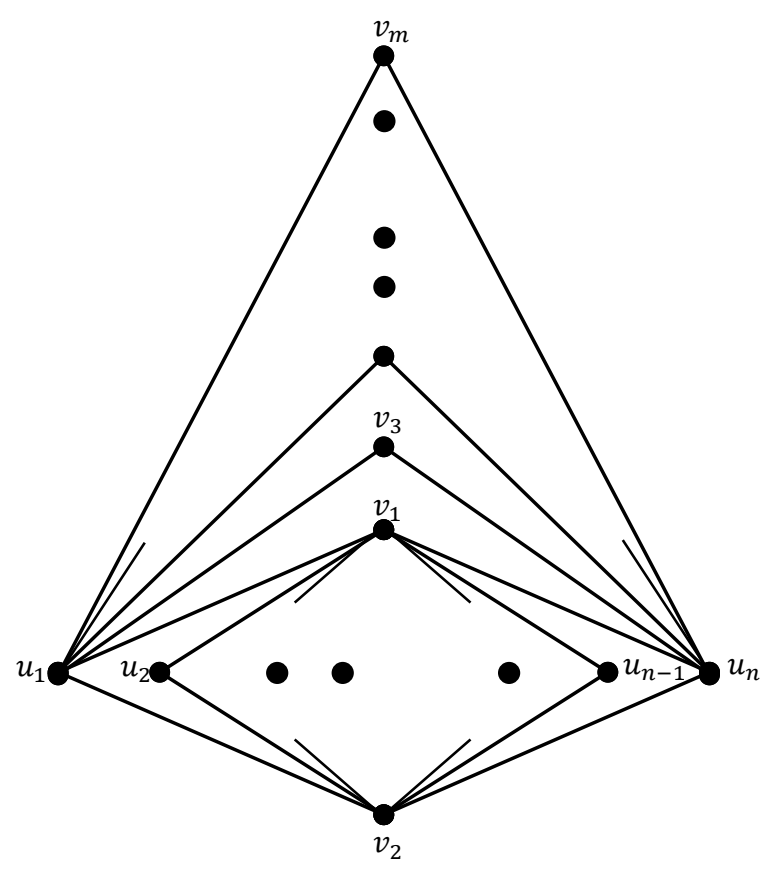

Gambar 2. Graf $P l_{m, n}$

\section{Teorema 3.3}

Graf $P l_{m, n}$ dengan $m, n \geq 3$ memiliki pelabelan super anti-ajaib tipe $(1,1,0)$.

\section{Bukti.}

Diberikan suatu kelas planar $P l_{m, n}(V, E)$ dengan jumlah titik $m+n$ yaitu $v_{1}, v_{2}, \ldots, v_{m}, u_{1}, u_{2}, \ldots, u_{n}$ dan $2 m+$ $2 n-4$ sisi. Didefinisikan fungsi bijektif $f: V \cup E \rightarrow C$ dengan $C=\{1,2, \ldots, 4 n-6\}$ sebagai berikut :

Pelabelan titik :

$$
\begin{aligned}
& f\left(v_{i}\right)=i \quad \text { untuk } 1 \leq i \leq m ; \\
& f\left(u_{i}\right)=i+m \text { untuk } 1 \leq i \leq n .
\end{aligned}
$$

Pelabelan sisi :

$$
\begin{array}{r}
f\left(v_{1}, u_{i}\right)=i+m+n, \text { untuk } 1 \leq i \leq n ; \\
f\left(v_{2}, u_{i}\right)=i+m+2 n, \text { untuk } 1 \leq i \leq n \\
f\left(u_{1}, v_{j}\right)=3(m+n)+1-2 j \\
\quad \text { untuk } 3 \leq j \leq m ; \\
f\left(u_{n}, v_{j}\right)=3(m+n)+2-2 j, \\
\text { untuk } 3 \leq j \leq m .
\end{array}
$$

Karena label-label terkecil diberikan pada himpunan titik-titik, maka pelabelan ini merupakan pelabelan super. Selanjutnya dapat dilihat bahwa jumlah muka dalam pada $P l_{m, n}$ adalah $m+n-3$. Muka yang terbentuk dari titiktitik $v_{1}, u_{1}, v_{3}, u_{n}, v_{1}$ memiliki bobot $10(m+n)-3$. Sebanyak $n-1$ muka yang terbentuk dari titik-titik $v_{l}, u_{l}, v_{2}, u_{l+1}, v_{1}$, untuk $1 \leq l \leq n-1$ memiliki bobot $6(m+n+l+1)$, dan sisanya yaitu sebanyak $m-3$ muka yang terbentuk dari titik-titik $u_{1}, v_{k}, u_{n}, v_{k-1}, u_{1}$, untuk $4 \leq k \leq m$ memiliki bobot $14 m+13 n+10-$ $6 k$.

Dapat dilihat bahwa setiap muka memiliki bobot yang berbeda, maka graf $P l_{m, n}$ dengan $m, n \geq 3$ memiliki pelabelan super anti-ajaib tipe $(1,1,0)$.

Akibat 3.4 Graf $P l_{m, n}$ dengan $m, n \geq 3$ memiliki pelabelan super anti-ajaib tipe $(1,1,1)$.

\section{KESIMPULAN}

Berdasarkan hasil dari penelitian, dapat ditarik kesimpulan sebagai berikut :

1. Graf $P l_{n}$ dengan $n \geq 5$ memiliki pelabelan super antiajaib tipe $(1,1,0)$ dan $(1,1,1)$.

2. Graf $P l_{m, n}$ dengan $n, m \geq 3$ memiliki pelabelan super anti-ajaib tipe $(1,1,0)$ dan $(1,1,1)$.

\section{DAFTAR PUSTAKA}

1. Baca, M. \& M. Miller, 2008, Supesr edge-antimagic graphs, Florida

2. Diestel, Reinhard, 2000, Graph theory electronic edition 2000. Springer-Verlac, New York

3. Harris, John, 2008, Combinatorics and graph theory, New York. 
4. Ramanjaneyulu, K., 2008, Anti-magic labellings of a class of planar graphs. Australian Journal of Combinatorics volume 41: 283-290

5. Rossen, Kenneth H., 2012, Discrete mathematics and its applications. McGraw-Hills, New York

6. Tilukay, M. I., Salman, A. N. M., Elviyenti, M., 2012, On super d-face antimagic total labelings of the corona product of a tree with $r$ copies of a path. AIP Conf. Proc. 1450, 218 